\title{
Monitoring Crustal Movements and Sea Level in Lanzarote
}

\author{
L. García-Cañada, M.J. Sevilla \\ Instituto de Astronomía y Geodesia (CSIC-UCM), \\ Facultad de Ciencias Matemáticas, Universidad Complutense de Madrid, 28040 Madrid, Spain. \\ lauragarcia@mat.ucm.es
}

\begin{abstract}
The Institute of Astronomy and Geodesy is measuring sea level variations in Lanzarote Island by two automated tide gauges of precision since 1993. In order to obtain "real" sea level variations a permanent GPS station has been installed near the tide gauges. The goal of this GPS station is to measurement vertical crustal movements in order to obtain absolute sea level variations removing these movements from tide gauge data.

A vertical tie with high accuracy between the reference point of the pillar where the GPS antenna is installed and the tide gauges bench marks is absolutely necessary. We have carried out this altimetric link yearly since year 2000. Methods of repeated geometric and trigonometric levelling of very short tracts have been used due to the great level difference existent.

The control of the local stability of the pillar where the GPS antenna has been established, is carried out by a micro-geodetic control network building around it. This network of 13 benchmarks has been regularly observed by classic and GPS geodetic techniques in years 2000, 2001, 2002, 2003 and 2004. The data of these campaigns have been processed by different types of adjustments in the same reference system. The precision of the measurements and the reliability of the networks have been calculated.

In this work the results obtained, the evaluation of the altimetric links and levelling campaigns, and the comparison of the levels of different measurements are presented.
\end{abstract}

Keywords. Sea level, crustal movements, geodetic networks and GPS.

\section{Introduction}

Changes in sea level are usually recorder by tide gauges, but their data corrupted by vertical land movements and they measure relative sea level. These vertical land movements at tide gauges have to be measure in order to obtain absolute sea level and separate crustal movements and sea level variations (Zerbini et al., 1996).

The aim of this work is monitoring the area where the tide gauges are installed using GPS and levelling techniques in order to provide absolute sea level instead "land relative" sea level. That is why continuous geodetic positioning of tide gauge bench marks (TGBMs) is required (IOC, 2000).

This allow to remove vertical motions of the land where tide gauge is attached from the sea level data and studying the correlation between relative sea level and crustal vertical movements.

\section{Tide gauges and GPS sites}

Lanzarote is the most Northeast island of the Canarian Archipelago, it is $100 \mathrm{~km}$ off the African coast and $1000 \mathrm{~km}$ off Iberian Peninsula. "Jameos del Agua" is a place in the north coast where the Institute of Astronomy and Geodesy has a geodynamic laboratory (Vieira, 1994).

There, the Corona volcano lava tube intersects with the ocean forming two lakes. It is an ideal place for very sensitive instruments to be hosted and a good area to sea level researches because there are not perturbations like winds and waves.

Two automated tide gauges of precision (Druck pressure sensors) are located in the two lakes that measure raw sea level in a relative reference system since 1993. Really near each tide gauge there is an altimetric bench mark.

A permanent GPS station has been installed to detect vertical velocity at tide gauges. It is located on the top of "La Casa de los Volcanes" building, which is a good place for a CGPS because it has a clear view of sky in all directions, area is free of interference sources and it is near tide gauges (Figure 1). 


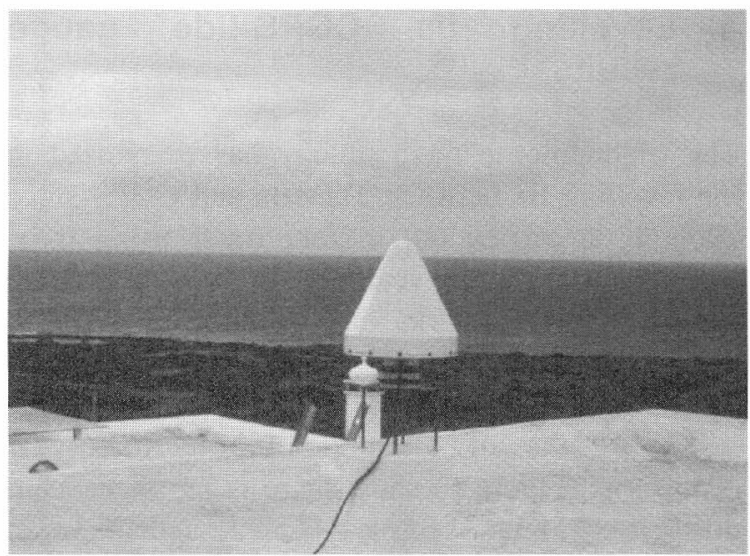

Fig. 1 Antenna of the CGPS Lanzarote station.

The instrumentation installed is a dual frequency code and phase measuring Ashtech Z-Surveyor receiver and Dorne Margolin choke ring ASH701945B_M antenna. It follows the guidelines of the IGS.

In addition tide gauges and a permanent GPS station there are other sensors to measure water and air temperature, pressure, humidity and gravity.

\section{Geodesic control}

Top of a building is not the best place to have a CGPS, that is why a micro geodetic control network has been designed and installed around it in order to monitor the stability of the monument and the building.

The network has 13 bench marks and the distance between these points is from 65 to $300 \mathrm{~m}$ (Figure 2). It has been regularly observed every year by classical geodetic techniques and GPS since year 2000.

But if a somewhat remote CGPS station is moving by an unknown amount relative to its tide gauge, then the absolute position of the tide gauge is being determined only as frequently as the levelling tie is being made (Figure 3 ).

The methodology to measure in the campaigns is different depending on the topography of the land.

Classical precise spirit levelling is use when height difference between bench marks is not so great. But when it is more important, trigonometric levelling with reciprocal and simultaneous vertical angles and geometric distance measure is used.

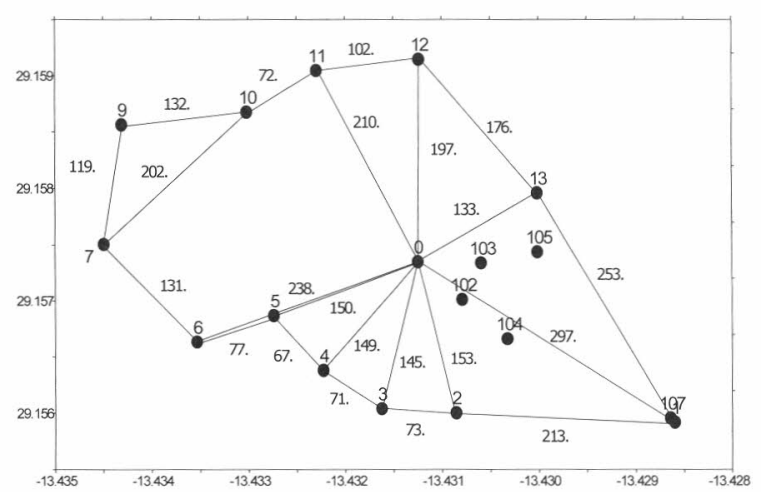

Fig. 2 Micro geodetic control network installed around CGPS (point number 0).

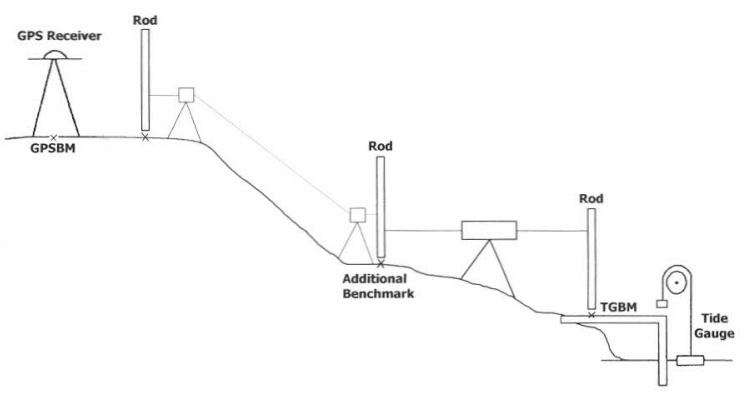

Fig. 3 Schematic of levelling tie between TGBM and CGPS.

In trigonometric method (Figure 4) the height difference between two points, $A$ and $B$, is calculated using (Sevilla and Romero, 1991):

$\Delta h=h i_{2}-h i_{1}=\left(R+h i_{1}\right) \frac{2 \cdot \sin \left(\frac{z_{1}-z_{2}}{2}\right) \cdot \sin \frac{\omega}{2}}{\cos \left(\frac{z_{2}-z_{1}}{2}+\frac{\omega}{2}\right)}$

where $z_{1}$ y $z_{2}$ are vertical angles measured, $h i_{1}$ y $h i_{2}$ are instruments heights, $R$ is terrestrial mean radio and $\omega$ is the angle that form the vertical of points $A$ and $B$ in the centre of the Earth.

The angle $\omega$ is calculated by:

$$
\omega=\frac{L}{R}
$$

where $L$ is the distance on the cord of ellipsoid, 


$$
L^{2}=\frac{d_{12}^{2}-\Delta H_{12}^{2}}{\left(1+\frac{h_{1}}{R}\right)\left(1+\frac{h_{2}}{2}\right)}
$$

$\Delta h$ is obtained by iteration method, using a approximated $L$ in the first iteration.

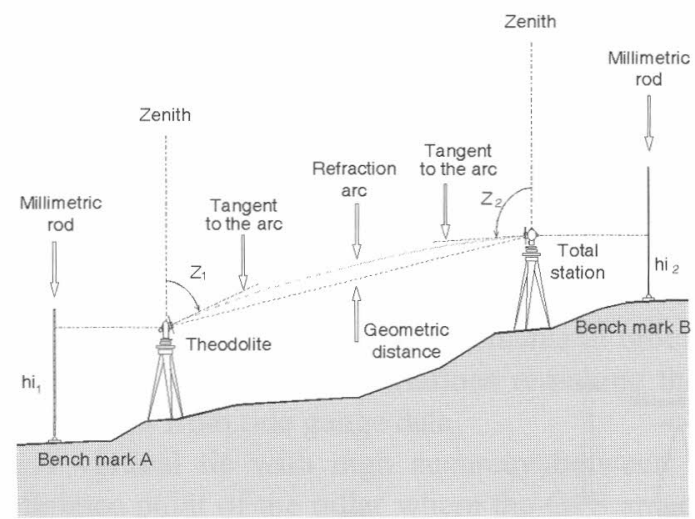

Fig. 4 Schematic of reciprocal and simultaneous trigonometric levelling.

The height difference using geometric levelling is calculated by:

$$
\Delta Z_{A B}=L_{A}-L_{B}
$$

where $L_{A}$ and $L_{B}$ are the readings in the rods located in the points $\mathrm{A}$ and $\mathrm{B}$ respectively (Figure 5).

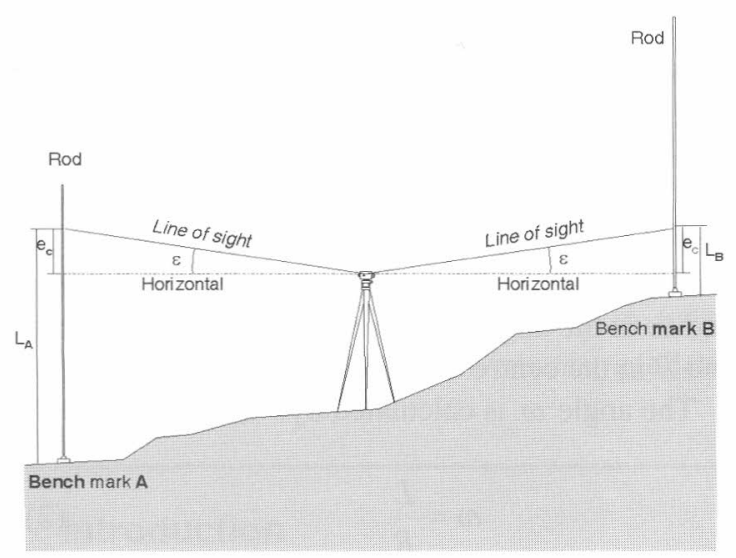

Fig. 5 Schematic of spirit levelling.

\section{Levelling tie CGPS-tide gauge results}

The trigonometric methodology has been used in the levelling tie between TGMBs and CGPS since 2000. It is carried out in four tracts using three auxiliary points in year 2000. In 2001 some additional bench marks had installed in order to have a better monitoring in the area in case any deformation were detected.

The results of altimetric profile in 5-year campaigns (Figure 6) show there is not significant differences in consecutive years, less than $3 \mathrm{~mm}$; this suggest that the tide gauge did not experience any uplift or subsidence relative to CGPS.

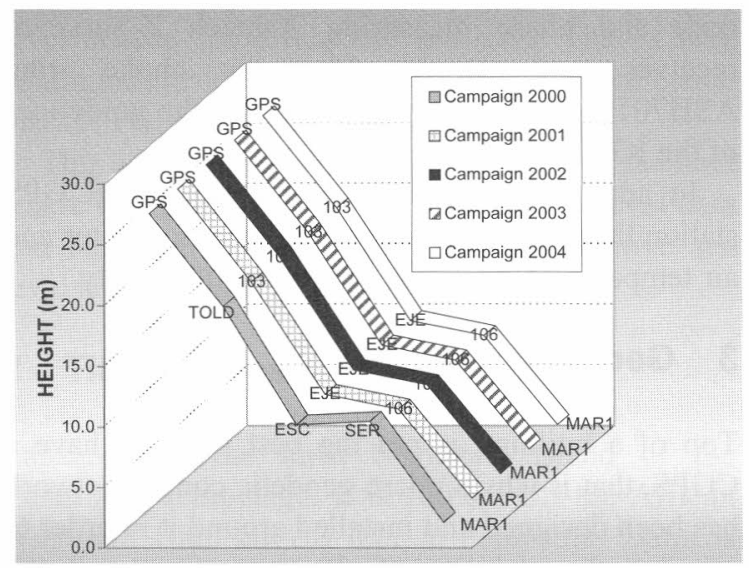

Fig. 6 Altimetric profiles GPS-MAR1 in 2000-2004 campaigns, with precision trigonometric levelling technique.

\section{Control network results}

The micro-geodesic control network (Figure 2) has been measurement yearly since 2000 too. Reciprocal and simultaneous trigonometric levelling is use to tie CGPS with network bench marks when there is visibility. Spirit levelling is carried out in the surveys for the external ring.

The least-square adjustment of the campaign data has been carried out with the method of variation coordinates using four different models:

1. Free network and equal weights (M1).

2. CGPS fixed and equal weights (M2).

3. Free network and weights inversely proportional to the distance (M3). 

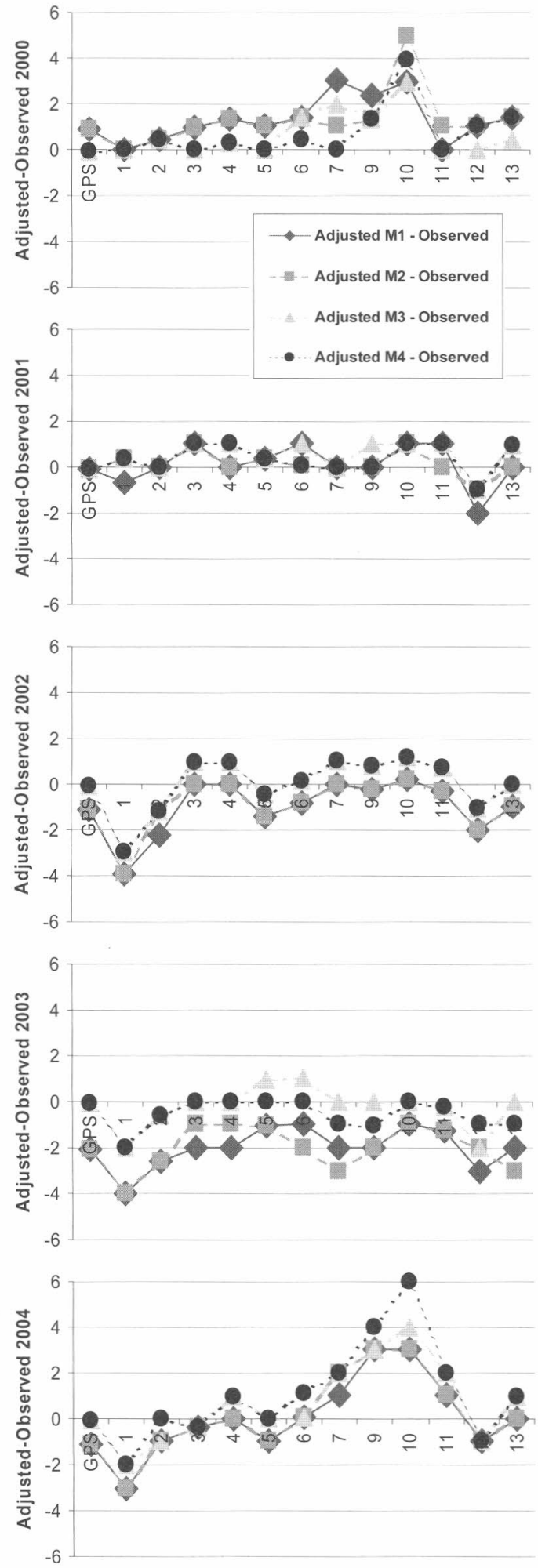

Fig. 7 Adjusted network results with four models in the five surveys.
4. CGPS fixed and weights inversely proportional to the distance (M4).

In Figure 7 we can see the difference between the difference height observed and adjusted with the four models in the 5 years and there is no significant difference in the results using one method or another.

If the results in the 5 years with one model are compared (Figure 8), a large subsidence at points 6 $(13 \mathrm{~mm})$ and $13(10 \mathrm{~mm})$ has been detected in the period 2000-2001. The reason was that these bench marks had been moved by a man-effect and they had to be repaired and the problem was solved since 2001 .

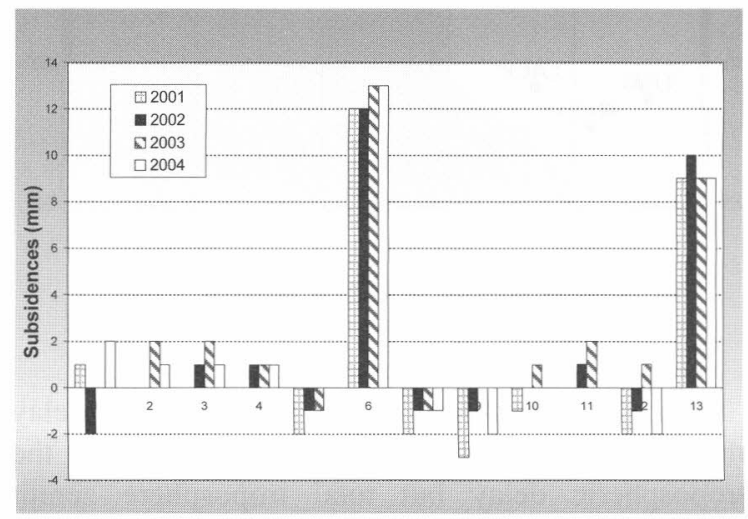

Fig. 8 Subsidences (in $\mathrm{mm}$ ) detected in years 2001, 2002, 2003 and 2004 in the control network points refer to 2000 campaign.

The results of the repeated precise levelling surveys showed no significant changes in height within the control network over the period from 2000 to 2004 . This confirms the stability of the monument and building on which the antenna GPS is located relative to the area.

\section{GPS time series}

CGPS data has been processed in a regional network of permanent stations formed by four IGS stations, MAS1, MADR. RABT and SFER, four EUREF stations, ALAC, CASC, CEUT and LPAL, and the Lanzarote station (LACV) (Figure 9).

The network is processed with Bernese v.4.2 software using IGS final precise orbits and Quasi Ionosphere Free (QIF) strategy for the ambiguity resolution (Hugentobler et al., 2001). Elevation cut off angle of $10^{\circ}$, elevation dependent observation 
weighting and the dry-Niell mapping function (Niell, 1996) has been used.

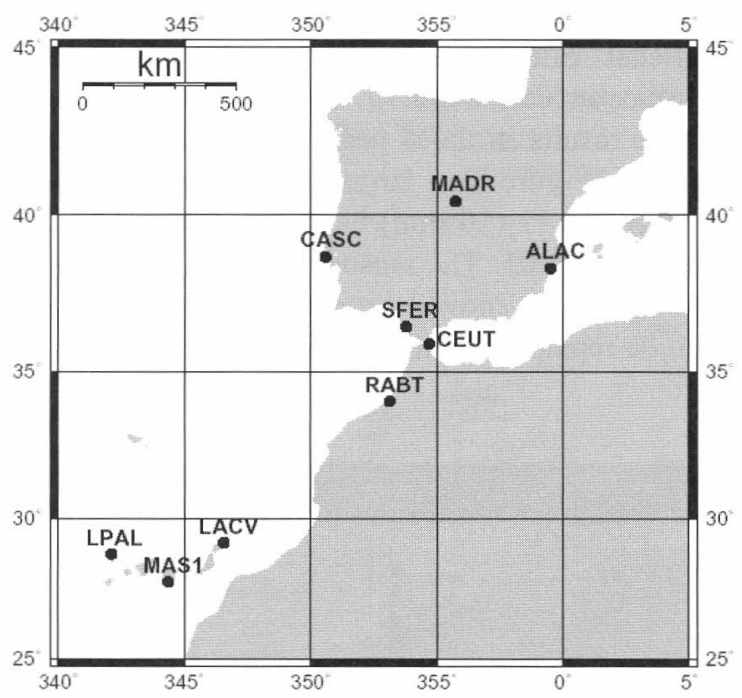

Fig. 9 Map of the CGPS regional network.

The Saastamoinen global tropospheric delay model is used to generate a priori values for the tropospheric delay but total troposphere zenith delay has been estimated for all the stations every hour. The ionosphere effect is eliminated introducing the ionosphere free linear combination of the observables.
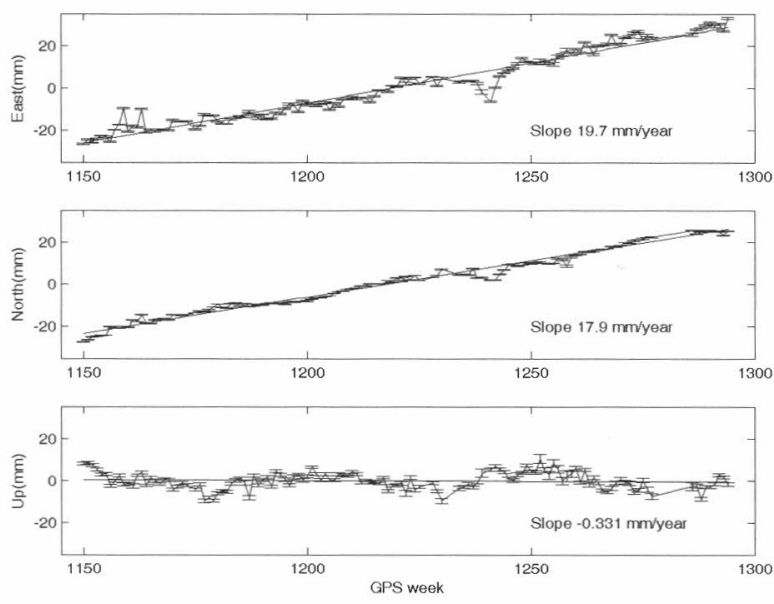

Fig. $10 \mathrm{LACV}$ weekly time series.
The ocean tide loading effect has been taken into account according to the GOT00.2 model. Amplitudes and phases of this model have been obtained from the H.G. Scherneck site (http://www.oso.chalmers.se/ loading/).

Sessions for 24 hours have been defined and for each session the network has been adjusted in Cartesian threedimensional coordinates in the ITRF2000 reference frame. The IGS stations MAS1, MADR and SFER have been considered fiducial stations constrain their ITRF2000 coordinates.

Daily coordinates and normal equations are calculated in this way and they are combined by ADDNEQ subroutine (Hugentobler et al., 2001) to obtain weekly solution.

Although time span is too short and there are some outlier period, preliminary results of the weekly time series (Figure 10) show there is no vertical rate and horizontal velocity in the same order of other stations in the same tectonic plate.

\section{Conclusions}

After measure sea level by tide gauges in Jameos del Agua (Lanzarote Island) since 1993 we adverted that geodetic techniques for monitoring rates of vertical land movements were needed if we want to obtain sea level change without land movements at tide gauges.

That is why a CGPS stations has been installed near tide gauges, a micro-geodesic control network has been established around it and it is surveyed regularly; levelling tie between CGPS and TGBM is carried out every year since 2000 .

The geodesic control network results over a period of four years show the monument of the GPS antenna and the building where the CGPS is, are stable and there is not any deformation between the pillar in the top of the building and the land is this area around it.

Due to the great height difference, the tie CGPSTGBMs is measure using precise trigonometric levelling techniques. The results of these campaigns confirm that the CGPS do not show any vertical deformation respect to TGBMs.

This ensures that the relative sea level measured by the tide gauges is not affected by land movements in the area, so it is representative of the surrounding area.

About time series of CGPS, preliminary results based on 2.5 years time span, suggest that the 
vertical component does not present any rate, but observations spanning a longer time period will be necessary to get more reliable values.

\section{Acknowledgement}

By the support coming from research project REN2001-2271, "Geodesic networks, space techniques and gravimetry applied to the study of the structure and dynamic of the crust in Canary" by Science and Technology Spanish Ministry.

\section{References}

Hugentobler, U., S. Schaer and P. Fridez (Edts.), 2001. Bernese GPS Software Version 4.2. Astronomical Institute. University of Berne.

IOC, 2000. Manual on sea-level measurement and interpretation. Volume 3 - Reappraisals and Recommendations as of the year 2000. Intergovernmental Oceanographic Commission. Manuals and Guides No. 14. IOC, Paris, 52pp.

Niell, A.E., 1996. Global mapping functions for the atmosphere delay at radio wavelengths. Journal of Geophysical Research, Vol. 101, No. B2, pp. 3227-3246.

Sevilla M. J. and P. Romero, 1991. Ground deformation control by statistical analysis of a Geodetic network in the caldera of Teide. Journal of Volcanology and Geothermal Research, Vol. 47 pp. 65-74. Elsevier Sc. Pub. Amsterdam.

Vieira, R., 1994. La estación geodinámica de Lanzarote. Serie Casa de los Volcanes. Monografía n⿳0 3, pp. 31-40.

Zerbini, S., H.P. Plag, T. Baker, M. Becker, H. Billiris, B. Bürki, H.G. Kahle, I. Marson, L. Pezzoli, B. Richter, C. Romagnoli, M. Sztobryn, P. Tomasi, M. Tsimplis, G. Veis, and G. Verrone, 1996. Sea level in the Mediterranean: a first step towards separating crustal movements and absolute sea level variations. Global and Planetary Change, 14, pp. 1-48. 